\title{
Tool life of ceramic wedges during precise turning of tungsten
}

\author{
Stanislaw Legutko ${ }^{1, *}$, Piotr Winiarski ${ }^{1}$, Tadeusz Chwalczuk ${ }^{1}$, Ludmila Marcincinova-Novakova ${ }^{2}$, and \\ Krzysztof Zak $^{3}$ \\ ${ }^{1}$ Poznan University of Technology, Pl. M. Sklodowskiej-Curie 5, 60-965 Poznan, Poland \\ ${ }^{2}$ Technical University of Kosice, Faculty of Manufacturing Technologies with a seat in Presov, \\ Bayerova 1, 08001 Presov, Slovakia \\ ${ }^{3}$ Opole University of Technology, Proszkowska 76, 45-758 Opole, Poland
}

\begin{abstract}
Properties, application and machinability of tungsten and its alloys have been demonstrated. The comparison of the tool life and wear of the wedges made of SiAlON and whisker ceramics during the precise turning at different cutting parameters have been presented. The CNC lathe DMG CTX 310 Ecoline and tungsten of $99.7 \%$ purity were used during the experiments. Only the wedge of whisker ceramics has proved to be sufficiently suitable and only for relatively low cutting speeds.
\end{abstract}

\section{Introduction}

Pure tungsten is a corrosion resistant metal which reacts with most acids only to a very small extent. Its pure form is very soft and very ductile which makes tungsten suitable for such processing as forging or pull broaching, however, even small additions of carbon or other elements make it stiff and very hard-to-process [1]. Tungsten alloys, due to their properties, are applied in many branches. In the branch of machine construction, tungsten alloys are used in manufacturing very hard cutting tools for titanium carbide is the major component of sintered carbides. Nowadays, they are composite materials consisting mainly of tungsten carbide and a bonding metal, most often cobalt; they are used in very demanding processing, with high cutting speeds where high abrasion resistance and hardness are required [2].

From the technical point of view, polycrystalline tungsten is the most important form possessing the highest content of pure metal. The properties of that material are closely related to the two factors:

- microstructure,

- presence, concentration and kind of impurities.

Tungsten microstructure which determines its properties to a high extent, depends on the way of its preparation (powder metallurgy, melting by an electron beam, refining, chemical application from the gas phase) and on subsequent operations (deformation, annealing, recrystallization). The properties of tungsten can be generalized in a number of items:

\footnotetext{
* Corresponding author: stanislaw.legutko@put.poznan.pl
} 
- plastically processed structure consisting of elongated crystals is stronger than that of annealed and recrystallized one; this is particularly visible in the case of strength in the direction of deformation,

- the lower is the working temperature and the more energy is stored during deformation, the higher is strength,

- the smaller is the grain size, the higher is strength,

- various methods of manufacturing (drawing, rolling, pull broaching) render various effects and even after completion of the process, the differences of the properties of materials obtained by the method of powder metallurgy and those obtained by another method are clearly visible.

Plasticity and strength are the properties due which tungsten is widely used as constructional material. As late as not long ago, tungsten was considered to be a brittle and hard-to-process material. At first, brittleness was attributed to the low level of the material purity obtained by the methods of powder metallurgy. However, single crystals of the highest purity obtained by means of electron beam refining, maintained their ductility in deformation even at the temperature of $-269^{\circ} \mathrm{C}$.

At the beginning of the twentieth century, the application of tungsten was limited to filaments and as alloy additive to steel. Today, its application is much more developed and includes such branches as lighting, electronics, technology of very high temperatures, medicine, aircraft industry, military applications sports and many more. About $4-5 \%$ of the world total tungsten production is used in the processes of the lighting industry. Nowadays, over $70 \%$ of artificial lighting is generated by glow-discharge tubes and the value is continuously growing. Tungsten is used for forming conductors and coils in filament lamps and as the material for electrodes in low and high pressure discharge lamps. Due to its properties, tungsten is used as the material for electric contacts, vacuum tight conducting connections. It is an ideal material for switches with high operation frequency, such as contact switches, voltage controls used in the automotive industry. Its alloys (W-Cu, W-Ag, WC-Ag) are used in manufacturing electric contacts operating at very high, medium and low voltages. In electronics, tungsten and its alloys are used as materials for electron emitters, components of vacuum lamps, sub-assemblies of laser printers and other printers, radiators of electronic devices, thin coatings in microelectronic devices and optoelectronic ones. In welding, it is used as the material for welding electrodes, heating coils for vacuum metalizing. Medicine is another area of tungsten application: anodes and cathodes in X-ray lamps used, for instance, in tomography, anti-radiation shelters or infrared reflector lamps are just a number of examples. In machine construction industry, the application of tungsten and its alloys includes, first of all: construction parts, combustion chambers in turbo engines, gyroscope rotors, servomotors in self-winding clocks, flow meter components, anti-vibration tool holders, counterweight loads and many others. Sports equipment, too, very often contains tungsten. Such components are, for example, professional hauling lines, diving loads, golf equipment, loads for runners, tennis racket loads, missiles for hunting rifles or counterweight in Formula 1 cars. In the chemical industry, tungsten plays an important role in manufacturing components for production of silica glasses, electrodes for the process of kaolinite melting, spinnerets for production of ceramic wool, crucibles for processing used nuclear fuels and melted metals or equipment for die casting. Aerospace industry is another area of tungsten application where tungsten and its alloys are used for some components of rocket engines, emitters in ion engines, parts of space nuclear reactors. Tungsten and military objects also have much in common. Its alloys are used in the production of tank ammunition reaching the speed of up to $1700 \mathrm{~m} / \mathrm{s}$, armour, grenades, counterweight in tanks. Due to its high hardness and density, tungsten is used in the production of cores of armour piercing sabot cores and composite full size missiles. In 
aircraft industry, the main application area is the production of aircraft wheel elements, counterweights and loads in airplanes and helicopters [3].

Sugita et al. [4] presents ultra-precision machining of tungsten alloy maximizing burnishing between the cutting tool and workpiece during cutting by combining strengths of the crystal grain and binder phase. Turning experiments conducted using workpieces of tungsten-based alloys $50 \mathrm{~mm}$ in diameter and $10 \mathrm{~mm}$ thick produced high-quality surface roughness $R z$ of $0.13 \mu \mathrm{m}$. Zebala and Kowalczyk [5] presents research of cutting process of high hardness composite materials such as sintered carbides based on the cobalt. The paper presents the influence of cutting parameters and cobalt content in a workpiece on the turning process of WC-Co with polycrystalline diamond (PCD) tool. This study was focused on the main component of cutting force $F_{c}$ and surface roughness $R a$. Choi et al. [6] presents analysis of the electrochemical behaviours of WC-Co alloy for micro ECM, microstructures of WC-Co with a sharp edge and good surface quality that were obtained by electrochemical milling and electrochemical drilling. The process performance can be improved by selecting the optimal combination of process parameters [7-10].

\section{Methodology of experimental investigations}

The purpose of the tests was to determine the suitability of selected ceramic wedges for cutting tungsten.

Within the investigation, precise turning of a shaft made of tungsten with purity of 99.7\% has been performed with the use of the following wedges:

- no. 1 of whisker ceramics - NTK - SNGN120408 T01020 WA1;

- no. 2 of SiAlON ceramics - Kennametal - SNGN120408 T01020;

- no. 3 of SiAlON coated ceramics- Kennametal - SNGN120408 T01020 coated with TiC.

Turning has been performed on a tungsten shaft with the diameter of $\varnothing 20 \mathrm{~mm}$, using a CNC lathe, DMG CTX 310 Ecoline. The lathe tool used in the machining process was PAFANA CSRN2 2020-12 fixed in the holder VDI B5 - 30x16/20 x40. Cutting wedge geometry was: $\lambda_{s}=-6^{\circ}, \gamma_{0}=-6^{\circ}, \kappa_{0}=75^{\circ}$.

Test conditions - constant parameters: feed $f=0.08 \mathrm{~mm} / \mathrm{rev}$, cutting depth $a_{p}=0.1 \mathrm{~mm}$; variable parameters: cutting speed $v_{c}[\mathrm{~m} / \mathrm{min}]$, cutting path $l_{s}[\mathrm{~mm}]$. For wedge no. 1 , cutting tests have been performed at the speeds of $40 \mathrm{~m} / \mathrm{min}, 80 \mathrm{~m} / \mathrm{min}$ and $150 \mathrm{~mm} / \mathrm{min}$; for wedge no. 2 the speeds of $30 \mathrm{~m} / \mathrm{min}, 80 \mathrm{~m} / \mathrm{min}$ and $150 \mathrm{~m} / \mathrm{min}$ were used; for wedge no. 3 , on the other hand, the cutting speed of $150 \mathrm{~m} / \mathrm{min}$ was used.

The wear of the ceramic wedges has been analysed and their life has been determined. Wear curves of the wedges have been drawn, photographs of them have been made and a mathematical model of the tested wedges life has been elaborated. $V B_{c}$ - the width of the corner wear band $=0.3 \mathrm{~mm}$ has been adopted as a wear criterion. Prior to each exchange of the cutting edge of the wedge it was necessary to measure the tool at each fixing of the wedge in the tool holder; the measurement was realized after it has been taken out from the machine. After the lathe tool has been relocated in the tool holder and the adequate value obtained from the measurement has been entered and the required path, depth and speed of cutting have been programmed with the use of the SINUMMERIK, machining has been started. After its completion, the wedge has been inspected under microscope and the indices of its wear: $V B_{c}, K E$ - cutting wedge shortening, $K B$ - the width of the abrasion groove on the rake face have been assessed, also by means of the AxioVision program. The operation has been performed for all the edges of the wedges under investigation. 


\section{Results and discussion}

\subsection{Analysis of the wedges wear}

Based on the investigation performed, it can be stated that only one of the tested wedges is suitable for turning tungsten. That is wedge no. 1 made by NTK company of whisker ceramics. As can be seen from the data presented in Table 1, wedge no. 2 made of SiAlON ceramic has significantly exceeded the blunting criterion at the first pass for the speed of $v_{c}$ $=150 \mathrm{~m} / \mathrm{min}$. Only at the speed of $v_{c}=30 \mathrm{~m} / \mathrm{min}$ the wedge durability made it possible to perform two passes. (measurement W2211 in which the wedge has not reached the criterion of blunting), which proves durability definitely too weak to machine tungsten. The wear of the wedge after the two passes is shown in Figure 1. The values of the wear indices $\left(V B_{c}\right.$, $K E$ and $K B$ ) for wedge 2 at the predetermined cutting parameters are shown in Table 1 . The durability of that wedge was not sufficient for the determination of the wear curves. The marking of each measurement used in Tables 1, 2 and 3 will be explained on the example of W1234 where the individual items denote: W - kind of material to be machined, in this case tungsten, 1 - wedge no., 2 - number of the wedge corner, 3 - number of the used $v_{c}$ parameter, 4 - number of the pass.
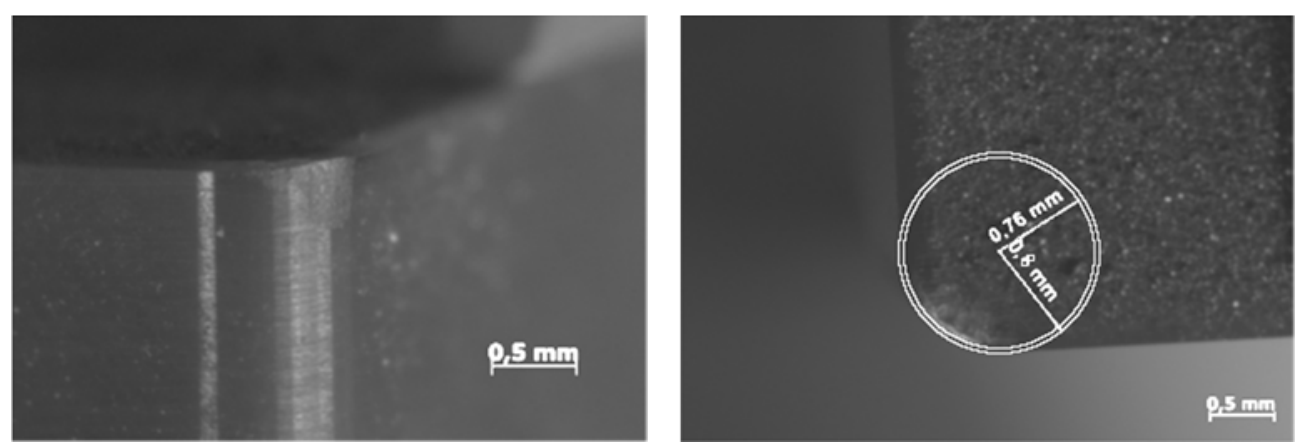

Fig. 1. The width of the wear band of wedge no. 2 after the second pass at the speed of $v_{c}=30 \mathrm{~m} / \mathrm{min}$, $V B_{c}=0.42 \mathrm{mmm}-$ on the left and cutting wedge shortening $K E=0.04 \mathrm{~mm}-$ on the right.

Table 1. Machining parameters and wear indices of wedge no. 2.

\begin{tabular}{|c|c|c|c|c|c|c|}
\hline Measurement & $\begin{array}{c}\boldsymbol{V} \boldsymbol{B}_{\boldsymbol{c}} \\
{[\mathbf{m m}]}\end{array}$ & $\boldsymbol{K} \boldsymbol{E}[\mathbf{m m}]$ & $\begin{array}{c}\boldsymbol{K B} \\
{[\mathbf{m m}]}\end{array}$ & $\begin{array}{c}\boldsymbol{T}_{\boldsymbol{s}} \\
{[\mathbf{m m}]}\end{array}$ & $\begin{array}{c}\boldsymbol{v}_{\boldsymbol{c}} \\
{[\mathbf{m} / \mathbf{m i n}]}\end{array}$ & $\boldsymbol{l}_{\boldsymbol{s}}[\mathbf{m m}]$ \\
\hline $\mathrm{W} 2111$ & 0.85 & 0.04 & 0.01 & 0.08 & 150 & 12 \\
\hline $\mathrm{W} 2211$ & 0.07 & 0.01 & 0.01 & 0.06 & 150 & 9.4 \\
\hline $\mathrm{W} 2212$ & 1.1 & 0.12 & 0.01 & 0.15 & 150 & 23 \\
\hline $\mathrm{W} 2321$ & 1.06 & 0.15 & 0.01 & 0.29 & 80 & 22.8 \\
\hline $\mathrm{W} 2421$ & 0.45 & 0.05 & 0.01 & 0.28 & 80 & 22.6 \\
\hline $\mathrm{W} 2521$ & 0.68 & 0.1 & 0.01 & 0.28 & 80 & 22.4 \\
\hline $\mathrm{W} 2621$ & 0.73 & 0.1 & 0.01 & 0.28 & 80 & 22.2 \\
\hline $\mathrm{W} 2731$ & 0.25 & 0.01 & 0.01 & 0.73 & 30 & 22 \\
\hline $\mathrm{W} 2732$ & 0.42 & 0.04 & 0.01 & 0.73 & 30 & 21.8 \\
\hline $\mathrm{W} 2831$ & 0.25 & 0.01 & 0.01 & 0.72 & 30 & 21.6 \\
\hline $\mathrm{W} 2832$ & 0.49 & 0.05 & 0.01 & 0.71 & 30 & 21.4 \\
\hline
\end{tabular}


Wedge no. 3 made of coated ceramic SiAlON, was not suitable for machining either - it showed much wear as early as after the first pass at the speed of $v_{c}=150 \mathrm{~m} / \mathrm{min}$. Due to the wear, was performed only one pass with that wedge (Fig. 2). The values of the wear indices $\left(V B_{c}, K E, K B\right)$ for wedge 3 at that pass are presented in Table 2 . The durability of that wedge, too, was not sufficient for the determination of the wear curves.

Table 2. Machining parameters and wear indices of wedge no. 3.

\begin{tabular}{|c|c|c|c|c|c|c|}
\hline Measurement & $\begin{array}{c}\boldsymbol{V} \boldsymbol{B}_{\boldsymbol{c}} \\
{[\mathbf{m m}]}\end{array}$ & $\boldsymbol{K E}[\mathbf{m m}]$ & $\begin{array}{c}\boldsymbol{K} \boldsymbol{B} \\
{[\mathbf{m m}]}\end{array}$ & $\boldsymbol{T}_{\boldsymbol{s}}[\mathbf{m m}]$ & $\boldsymbol{v}_{\mathbf{c}}[\mathbf{m} / \mathbf{m i n}]$ & $\boldsymbol{l}_{\boldsymbol{s}}[\mathbf{m m}]$ \\
\hline $\mathrm{W} 3111$ & 0.56 & 0.10 & 0.01 & 0.14 & 150 & 21.2 \\
\hline
\end{tabular}
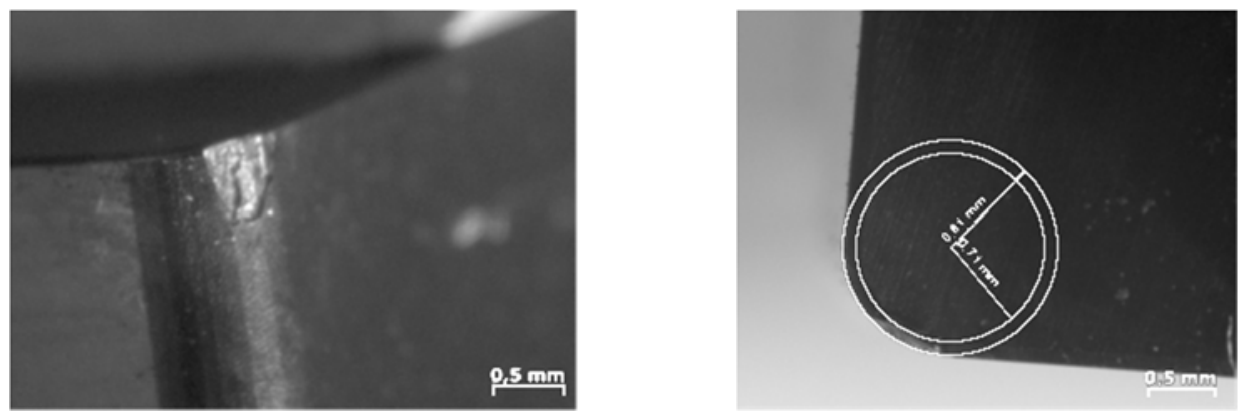

Fig. 2. The width of the wear band of wedge no. 3 after the first pass at the speed of $v_{c}=150 \mathrm{~m} / \mathrm{min}$, $V B_{c}-0.56 \mathrm{~mm}-$ on the left and wedge shortening, $K E=0.1 \mathrm{~mm}-$ on the right.

Wedge no. 1 made of whisker ceramic has shown sufficient durability for performing over a dozen passes with one corner at the cutting speed of $v_{c}=40 \mathrm{~m} / \mathrm{min}$. The measurement results are presented in Table 3.

Table 3. Machining parameters and wear indices of wedge no. 1.

\begin{tabular}{|c|c|c|c|c|c|c|}
\hline Measurement & $\boldsymbol{V}_{\boldsymbol{c}}[\mathbf{m m}]$ & $\boldsymbol{K} \boldsymbol{E}[\mathbf{m m}]$ & $\boldsymbol{K} \boldsymbol{B}[\mathbf{m m}]$ & $\boldsymbol{T}_{\boldsymbol{s}}[\mathbf{m m}]$ & $\boldsymbol{v}_{\boldsymbol{c}}[\mathbf{m} / \mathbf{m i n}]$ & $\boldsymbol{l}_{\boldsymbol{s}}[\mathbf{m m}]$ \\
\hline $\mathrm{W} 1111$ & 0.01 & 0.01 & 0.01 & 0.165 & 80 & 13.2 \\
\hline $\mathrm{W} 1112$ & 0.13 & 0.01 & 0.01 & 0.16 & 80 & 13 \\
\hline $\mathrm{W} 1114$ & 0.24 & 0.01 & 0.01 & 0.16 & 80 & 12.7 \\
\hline $\mathrm{W} 1116$ & 0.35 & 0.05 & 0.01 & 0.16 & 80 & 12.5 \\
\hline $\mathrm{W} 1221$ & 0.2 & 0.01 & 0.01 & 0.08 & 150 & 12.4 \\
\hline $\mathrm{W} 1222$ & 0.43 & 0.01 & 0.01 & 0.08 & 150 & 12.2 \\
\hline $\mathrm{W} 1331$ & 0.01 & 0.01 & 0.01 & 0.30 & 40 & 12 \\
\hline $\mathrm{W} 1332$ & 0.01 & 0.01 & 0.01 & 0.30 & 40 & 11.8 \\
\hline $\mathrm{W} 1333$ & 0.01 & 0.01 & 0.01 & 0.29 & 40 & 11.6 \\
\hline $\mathrm{W} 1334$ & 0.05 & 0.01 & 0.01 & 0.29 & 40 & 11.4 \\
\hline $\mathrm{W} 1335$ & 0.06 & 0.01 & 0.24 & 0.28 & 40 & 11.2 \\
\hline $\mathrm{W} 1336$ & 0.07 & 0.01 & 0,24 & 0,28 & 40 & 11 \\
\hline $\mathrm{W} 1337$ & 0.08 & 0.01 & 0.24 & 0.27 & 40 & 10.8 \\
\hline $\mathrm{W} 1338$ & 0.11 & 0.01 & 0.24 & 0.27 & 40 & 10.6 \\
\hline $\mathrm{W} 1339$ & 0.11 & 0.01 & 0.24 & 0.58 & 40 & 23 \\
\hline $\mathrm{W} 13310$ & 0.12 & 0.01 & 0.24 & 0.57 & 40 & 22.8 \\
\hline $\mathrm{W} 13311$ & 0.13 & 0.01 & 0.24 & 0.57 & 40 & 22.6 \\
\hline $\mathrm{W} 13312$ & 0.17 & 0.01 & 0,24 & 0.56 & 40 & 22.4 \\
\hline $\mathrm{W} 13313$ & 0.19 & 0.01 & 0.24 & 0.56 & 40 & 22.2 \\
\hline $\mathrm{W} 13314$ & 0.23 & 0.01 & 0.24 & 0.55 & 40 & 22 \\
\hline $\mathrm{W} 13315$ & 0,28 & 0.01 & 0.24 & 0.55 & 40 & 21.8 \\
\hline $\mathrm{W} 13316$ & 0.33 & 0.03 & 0.24 & 0.54 & 40 & 21.6 \\
\hline
\end{tabular}



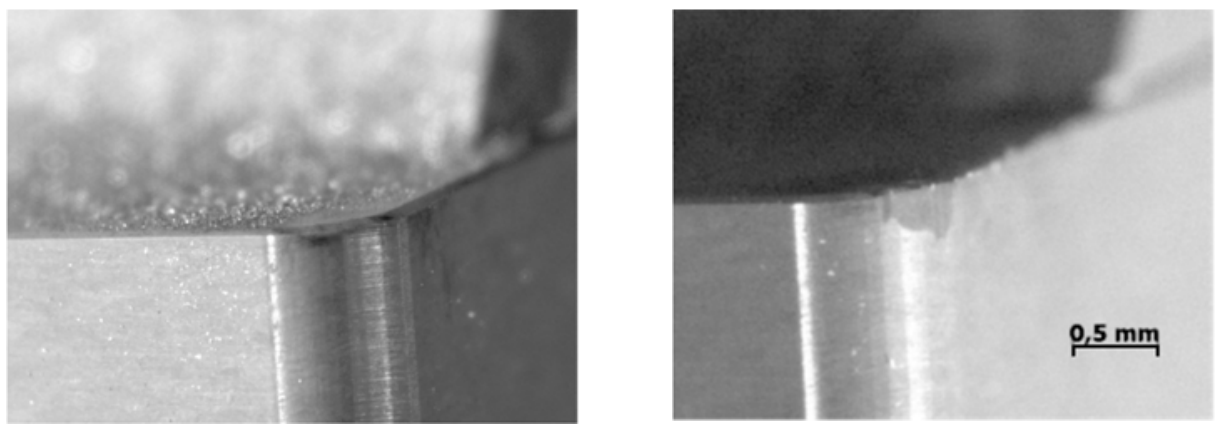

Fig. 3. The wear of the flank face of wedge no. 1 after the third pass at the cutting speed of $40 \mathrm{~m} / \mathrm{min}$ - no symptoms of wear (on the left) and the width of the wear band of wedge no. 1 after the $16^{\text {th }}$ pass with the same corner at the cutting speed of $40 \mathrm{~m} / \mathrm{min}$ - edge blunting criterion reached $V B_{c}=0.33$ $\mathrm{mm}$ (on the right).

As the subsequent passes were performed, one could observe a groove appearing on the rake face as result of chip friction against the wedge. Its size just before reaching the blunting criterion $V B_{c}=0.30 \mathrm{~mm}$ are clearly visible in Fig. 4 .

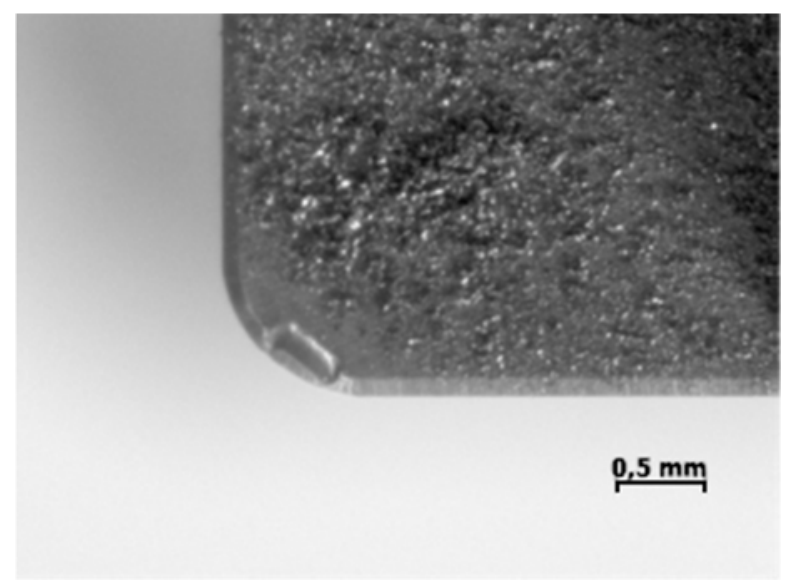

Fig. 4. Groove on the rake face of wedge no.1 just before reaching the blunting criterion $V B_{c}=0.30$ $\mathrm{mm}$.

\subsection{Determination of the wear curves}

Based on the measurements of the wear index $V B_{c}$ of wedge no.1 wear curve has been prepared (Fig. 5, 6) which has made it possible to determine its life period and to perform further calculations in order to make a mathematical model for predicting the wedge durability. For the speed of $v_{c}=80 \mathrm{~m} / \mathrm{min}$, the wedge corner endured 6 passes, which was sufficient for the determination of the wedge wear curve (Fig.5). Only two passes before reaching the blunting criterion of $V B_{c}=0.3 \mathrm{~mm}$ have been performed for the speed of $v_{c}=$ $150 \mathrm{~m} / \mathrm{min}$, which allowed only the determination of the diagram with a straight line (Fig. $6)$. 

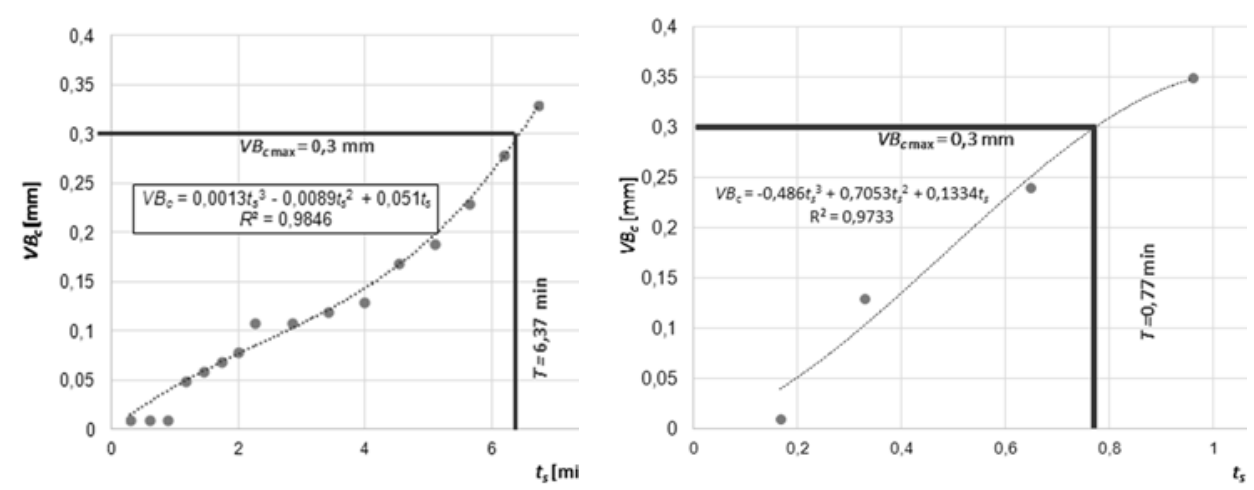

Fig. 5. Wear curve of wedge no. 1 for: $v_{c}=40 \mathrm{~m} / \mathrm{min}$ (on the left) and for $v_{c}=80 \mathrm{~m} / \mathrm{min}$ (on the right); $f=0.08 \mathrm{~mm} / \mathrm{rev}, a_{p}=0.1 \mathrm{~mm}$.

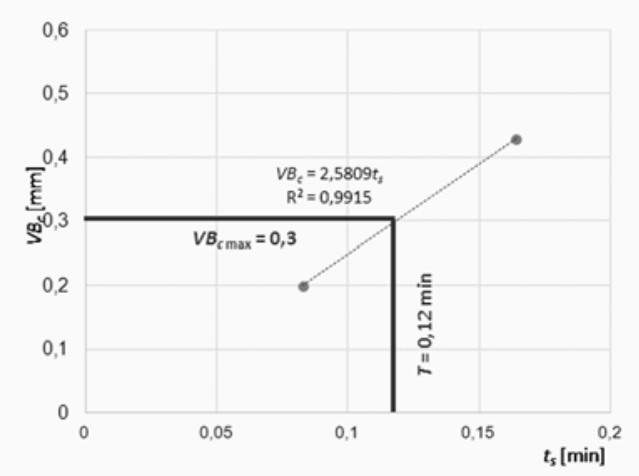

Fig. 6. Wear curve of wedge no. 1 for: $v_{c}=150 \mathrm{~m} / \mathrm{min} f=0.08 \mathrm{~mm} / \mathrm{rev} a_{p}=0.1 \mathrm{~mm}$.

During the analysis of the wedge shortening index, it could be noticed that the shortening occurred after the wedge blunting criterion $V B_{c}$ had been reached, which is clearly visible when comparing the two diagrams presented in the Figure 7 . As can be seen in Fig. 7, the $K E$ wear index rises sharply when wear index $V B_{C}$ reaches criterial value of $0.3 \mathrm{~mm}$. In the upper diagram, the curve of wear intensity (the red one) has also been drawn.

Based on the analysis of the wear curves, the edge life periods have been determined for the individual cutting speeds: $v_{c}=40 \mathrm{~m} / \mathrm{min}-T=6.37 \mathrm{~min} ; v_{c}=80 \mathrm{~m} / \mathrm{min}-T=0.77 \mathrm{~min}$; $v_{c}=150 \mathrm{~m} / \mathrm{min}-T=0.12 \mathrm{~min}$.

On the basis of the results obtained, a mathematical model of the wedge life has been elaborated for wedge no. 1 using classical commonly known procedure [11]:

$$
T=\frac{271034.12}{v_{c}^{2.91}}
$$

Based on the mathematical model, a diagram of the wedge life period as a function of the cutting speed has been realized (Fig. 8). 


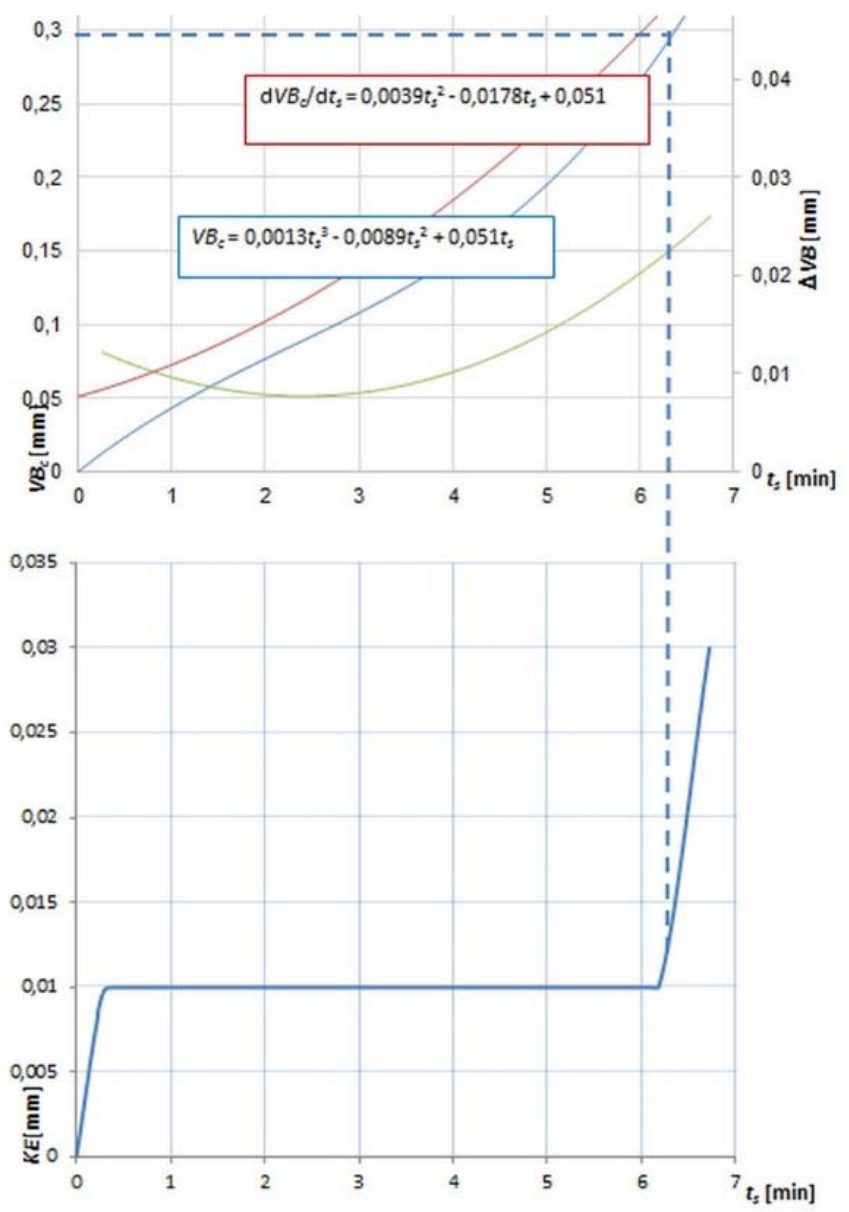

Fig. 7. A comparison of diagrams illustrating the moment of appearance of the wear index $K E$, wedge no 1 , for: $v_{c}=40 \mathrm{~m} / \mathrm{min}, f=0.08 \mathrm{~mm} / \mathrm{rev}, a_{p}=0.1 \mathrm{~mm}$.

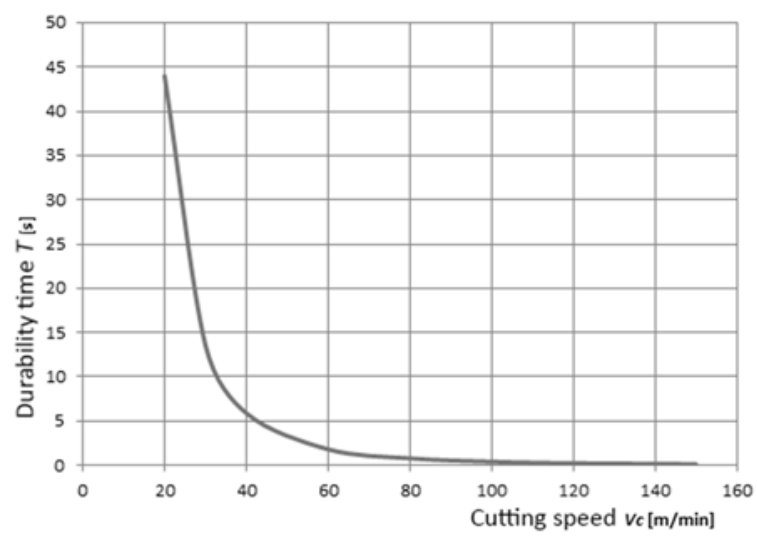

Fig. 8. Wedge life period as a function of the cutting speed determined on the basis of the mathematical wedge life model for wedge no. 1 


\section{Conclusions}

Tungsten has proved to be a hard-to-machine material. The tool material must meet very high requirements. Only the wedge made of whisker ceramic has proved to be suitable and only for relatively low cutting speeds. On the basis of the performed tests and inspections, the following conclusions can be formulated:

- In turning of tungsten using ceramics wedges abrasive wear was prevailing. This was proved by the wear band appearing on the wedge corner and the groove on the rake face which had appeared during cutting by a wedge of whisker ceramic. Small influence of chemical wear on the total wear of the wedge was due to the high resistance of ceramic materials to this kind of wear. Most probably, adhesion, thermal and diffusion wear also occurred, but its small influence on the total wedge wear has prevented detection of its presence.

- In the process of turning no built-up-edge formation has been found due to the brittleness of the material under machining and to the formation of splinter chip. The absence of built-up-edge has also eliminated formation of dents and has influenced the small portion of adhesion wear which arises mainly in the zone of built-up-edge formation.

- Wedge no. 1 made of whisker ceramic has proved to be the most durable one. This was due to abrasion resistance better than that of the SiAlON wedges. The abrasion is the kind of wear which has dominated in turning of the tungsten shaft.

- Fine chip present in machining proves high brittleness of tungsten due to impurity. Even small quantities of impurities - in this case $0.3 \%$ - has changed the ductile form of tungsten into brittle one.

- The obtained test results allowed the elaboration of dependence of the wedge life on the cutting speed.

- Wedges made of whisker ceramic can be suitable for turning of tungsten. However, high cutting speeds result in very quick wear of those wedges.

\section{References}

1. S. Stolarz, W. Rutkowski, Tungsten and molybdenum (PWN, Warszawa, 1961)

2. http://www.baildonit.com.pl

3. E. Lassner, W. Schubert, Tungsten: Properties, Chemistry, Technology of the Element, Alloys, and Chemical Compounds (Kulwer Academic / Phenum Publ., New York, 1999)

4. N. Sugita, K. Nishioka, M. Mitsuishi, Int. J. of Autom. Techn., 5, 3, 320 (2011)

5. W. Zebala, R. Kowalczyk, Int. J. of Adv. Man. Techn., 77, 9-12, 2241 (2015)

6. S.H. Choi, B.H. Kim, H.S. Shin, D.K. Chung, C.N. Chu, J. of Mat. Proc. Techn., 213, 4, 621 (2013)

7. G.M. Krolczyk, P. Nieslony, J.B. Krolczyk, I. Samardzic, S. Legutko, S. Hloch, S. Barrans, R.W. Maruda, Measurement, 70, 203 (2015)

8. G.M. Krolczyk, J.B. Krolczyk, R.W. Maruda, S. Legutko, M. Tomaszewski, Measurement, 88, 176 (2016)

9. R.W. Maruda, G.M. Krolczyk, E. Feldshtein, M. Szydlowski, S. Legutko, F. Pusavec, A. Sobczak-Kupiec, Int. J. of Mach. Tools and Man., 100, 81 (2016)

10. S. Wojciechowski, T. Chwalczuk, P. Twardowski, G.M. Krolczyk, Arch. of Civ. and Mech. Eng., 15, 4, 798 (2015)

11. G.M. Krolczyk, P. Niesłony, S. Legutko, Arch. of Civ. and Mech. Eng., 15, 2, 347 (2015) 